\title{
O trabalho cultural e a pedagogia do teatro
}

\author{
Rogério Moura
}

\footnotetext{
ris
} ste é um momento da história brasileira propício para discutir o papel dos educadores e dos recursos (humanos e materiais) disponíveis para enfrentar o tema da formação das novas geraçóes. Violência, aumento da exclusão social e uma crescente dificuldade no diálogo entre governo e sociedade no âmbito da gestão de políticas públicas para jovens remetem esta discussão a Giroux, autor que propiciou um novo olhar sobre o campo da Pedagogia Cultural, ao abordar de forma sinérgica os conceitos de cultura, educação e democracia. Para Giroux:

"Nesta época da nossa história, é especialmente importante que artistas, educadores e outros trabalhadores culturais desenvolvam uma definição mais ampla da instrução e da prática pedagógica como uma forma de política cultural." (1999, p. 277)

Este escopo mais amplo e abrangente em termos da instrução e da prática pedagógicas vem se traduzindo, no Brasil, entre outras iniciativas, por atores estatais, que no âmbito do ensino médio aliam secretarias de estado e organizações da sociedade civil e do setor privado, visando instalar programas de formação de jovens das mais diversas naturezas dentro do sistema escolar formal.
Assim, a prática pedagógica e a instrução expandem-se até se traduzirem por programas pedagógicos, artísticos e culturais, dentre os quais citamos, no Estado de $S$ Paulo, "Parceiros do Futuro", "Programa Arquimedes" e "Programa Profissão", geridos por diversas secretarias de Estado. Outras iniciativas apontam para a estruturação de centros culturais dentro da rede escolar através de parcerias entre o Estado e entidades de direito privado.

Observa-se uma transformação cujo alcance pleno ainda não se conhece, na qual o Estado deixa de atuar sozinho no campo da gestão da educação, sendo acompanhado por entidades e representantes do setor privado na instalação de atividades pedagógicas, artísticas e culturais para jovens, com a suposta intenção de melhorar a sua inserção social.

Desde já surgem novas abordagens possíveis para a relação educador-educando, bem como para compreender o jogo de forças entre cultura do centro (de onde surgem as novas propostas pedagógicas) e cultura da margem (onde estão os supostos objetos destas propostas pedagógicas, os jovens).

A complexidade no campo da formação das novas gerações, por sua vez, combinando os campos da Pedagogia, da Cultura e do Direito, traz a urgência de uma rediscussão acerca dos

Rogério Moura é diretor teatral; mestre em Artes pela Escola de Comunicaçōes e Artes da USP; doutorando da Faculdade de Educação da USP. 
modelos de formação de educadores. Esses modelos não somente não contemplam as mudanças verificadas a partir dos anos 1990 na relação escola-Estado-sociedade, como também não conseguem lançar um novo olhar sobre o direito educacional, incluindo-se aí as mudanças e discussões que surgiram a partir da nova Lei de Diretrizes e Bases da Educação Nacional, do Estatuto da Criança e do Adolescente e das portarias e decretos subseqüentes sancionados pelo Estado na segunda metade da década de 1990.

Os programas culturais, artísticos e educacionais implantados principalmente na periferia da cidade de São Paulo no final dos anos 1990, alguns operando dentro das escolas do nível médio, trazem para a comunidade escolar e para os educadores atuantes a necessidade de ouvir e repensar constantemente o planejamento das atividades pedagógicas.

No contexto da formação propriamente dita de jovens e adolescentes, os índices de exclusão social, de pobreza extrema e de violência na periferia terminam por contribuir muitas vezes para uma atitude de rebeldia e mesmo de negação por parte dos adolescentes em tomar parte das atividades oferecidas, já que a princípio estas são identificadas como advindas de um Estado até então omisso na tarefa de proteger cidadãos e de oferecer-lhes qualidade de vida na forma de atividades culturais e de formação geral.

Pesquisa realizada por este autor ao longo de dois anos na periferia de São Paulo mostrou que os jovens passam a interagir com as propostas pedagógicas oferecidas por estes programas, na medida em que se tornam agentes do próprio processo de ensino-aprendizagem, ou seja, na medida em que 'são ouvidos'.

Coloca-se um desafio duplo para os programas em discussão: aprender a ouvir o grupo alvo para o qual a política pública está direcionada e promover a revisão dos fundamentos que justificam a sua implantação. Certamente isto não exime o educador da responsabilidade de atuar num plano mais político de formação de jovens e adolescentes, mas, pelo contrário, obriga-o a estabelecer um meio termo entre atender ao conteúdo do programa pedagógico, quando houver, e ao mesmo tempo ouvir os principais interessados.

Educação e Cultura desta forma constroem um sentido amplo para o processo de formação de jovens. Uma atitude mais política e uma postura mais enérgica na luta por uma formação pedagógica e cultural de qualidade passam a ser os novos desafios das políticas educacionais em grande parte dos países latino-americanos. Trata-se de desenvolver uma postura nova de educadores que passem a lutar para que o processo educacional, numa perspectiva abrangente que envolva tanto o ensino formal como o informal, seja abordado a partir da idéia de uma política cultural preocupada com a formação plena das novas gerações.

Esta discussão precisa abraçar as interfaces entre os conceitos de cultura e trabalho, como entende Chauí. Para a autora, a cultura "[...] é entendida por um duplo registro: no sentido antropológico amplo de invenção coletiva e temporal de práticas, valores, símbolos e idéias que marcam a ruptura do humano em face das coisas naturais com a instituição da linguagem, do trabalho [...]" (1992, p. 39). Nesse primeiro sentido, cultura é "um fato e somos todos seres culturais”. Mas constitui-se aí um segundo sentido para a palavra, considerada então como: "trabalho, entendido como o movimento pelo qual os seres humanos são capazes de uma relação com o ausente e o possível, são capazes de negar as condições imediatas de sua experiência e são capazes de criar o novo como plenamente humano".

A interface entre trabalho e cultura conduz à possibilidade de pensar o trabalho artístico, portanto cultural, como processo produzido coletivamente por sujeitos. Para "criar o novo como plenamente humano" é preciso, no entanto, que educadores/trabalhadores culturais em teatro reconheçam que a cultura não é somente um legado de crenças e costumes, monumentos ou tradiçóes estéticas que se transmutam em obras acabadas sobre um palco, mas é tudo aquilo produzido pelo esforço humano de auto-su- 
peração, incluindo o esforço de um bailarino na construção de uma partitura coreográfica, o incansável trabalho de construção do personagem por um ator ou a interação de jogadores no jogo teatral. Trabalho, aqui entendido na sua acepção cultural, está relacionado a processo, ainda que este se dê num contexto de grande dificuldade, como o da periferia das megacidades.

Neste processo, o conceito de cultura se democratiza para abranger todas as classes e extratos sociais da sociedade, compostos de seres humanos capazes de "negar as condições imediatas da sua experiência e criar o novo como plenamente humano". É preciso, no entanto, que educador e educando visualizem o exercício da cultura manifesto através do esforço de construção do trabalho cultural.

Desta forma, será então trabalho cultural o esforço de educar pela estética, de construir um papel/personagem, de realizar um jogo teatral e de aliar a informalidade das práticas sociais dos sujeitos periféricos ao ímpeto formativo dos programas pedagógico-culturais do Estado.

$\mathrm{Na}$ verdade, para Chauí, o sentido de uma "política de cidadania cultural" 1 é um processo a ser construído através de uma vontade política claramente determinada, que possibilite a produção dos diversos sujeitos no contexto dos respectivos processos de criação. O que se aponta aí é a necessidade de se superar o déficit histórico do poder público no cumprimento de seu papel como gestor da cultura e disponibilizador de bens culturais a todos os segmentos da sociedade brasileira.

Sabemos que o problema da formação das novas gerações atinge tanto países da periferia do capitalismo global, como Brasil, México, Argentina e outros, quanto países centrais, entre os quais destacaríamos França e Alemanha. Os dois grupos de países apresentam alto índice de desemprego entre jovens, fenômeno este identificado pelo Relatório do PNUD (2000) como "falta de oportunidades para jovens urbanos".

Cabe frisar que este fenômeno diz respeito à dificuldade dos Estados Nacionais em garantir formação plena e inserção social às novas gerações, num ambiente de fragilidade das políticas sociais advinda dos processos acelerados de globalização econômica e financeira, por sua vez propiciados pelas reformas do último decênio do século XX.

As reformas do Estado nos anos 1990 na América Latina culminaram com uma intensa internacionalização do capital e drásticos cortes nos orçamentos sociais. Atentando para as mudanças verificadas tanto em nível local (naçôes), como em nível global, cabe questionar a configuração econômica e social desigual que vai se delineando e propor alternativas a esse modelo global de sociedade, marcado pela 'demanda do mercado'. Somam-se então ao enorme déficit nas políticas sociais vigentes no Brasil dos anos 1990, as transformaçôes em âmbito global acima mencionadas.

\section{papel do teatro na construção das oportunidades para jovens}

O trabalho de teatro com jovens na periferia da megacidade busca contribuir para corrigir as distorções sociais criadas por um modelo de economia global, que na periferia capitalista

1 "Ao definirmos política cultural como Cidadania Cultural e a cultura como direito, estamos operando com os dois sentidos da cultura: como um fato ao qual temos direito como agentes ou sujeitos históricos; como um valor ao qual todos têm direito numa sociedade de classes que exclui uma parte de seus cidadãos do direito à criação e à fruição das obras de arte. Nossa política cultural tem se proposto a enfrentar o desafio de admitir que a cultura é simultaneamente um fato e um valor, a enfrentar o paradoxo no qual a cultura é o modo de ser dos humanos e no, entanto, precisa ser tomada como um direito daqueles humanos que não podem exercer plenamente o seu ser cultural - no caso, a classe trabalhadora." (Chauí, 1992, p. 39) 
planetária produz enormes 'prisões sociais', compreendidas como as áreas dos bolsões de pobreza apontados por Bruno (1997, p. 43). As populações aí localizadas não conseguem se conectar ao que Castells (2000) chamou de Paradigma Informacional, associado aos conceitos de produção, de experiência e de poder ${ }^{2}$. Esta situação é piorada pela extrema concentração de renda e riqueza vigentes no Brasil, cujo $\mathrm{IDH}^{3}$ é baixíssimo, dada a dimensão de sua economia, sendo a distribuição de renda, de acordo com a ONU, a terceira pior do mundo.

Busca-se compreender então, qual seria o papel da educação estética numa sociedade tão desigual. É neste contexto que o Jogo Teatral, aqui destacado pela perspectiva de uma praxis, estimula nos jovens e adolescentes excluídos uma leitura crítica da realidade na qual estão inseridos, para que possam encontrar formas de transformar sua existência e assumir o que Sen (2000) classificou como sua "condição de agente". Não se trata então de um elenco de atividades teatrais voltadas para o lazer ou para sublimar o grave problema social a que estão submetidos estes jovens, mas de articular uma prática artística à realidade social, ao mesmo tempo demonstrando o claro papel que a linguagem do teatro pode desempenhar na sociedade e contribuindo para uma reflexão capaz de gerar, nos níveis simbólico e concreto, a sustentabilidade das práticas sociais dos sujeitos.

Este jogo social propiciado pelo exercício pedagógico-estético reconstrói a responsabilidade dos sujeitos, atores do e no processo, que passam a compreender o sentido de suas práticas, avaliando-as e experimentando o sentido de justiça que deve permear a relação entre dois indivíduos.

A teoria dos Jogos Teatrais vem se consolidando no Brasil há mais de trinta anos, a partir da vasta contribuição teórica que ia de John Dewey a Viola Spolin e Bertolt Brecht, sendo sob certos aspectos acentuadamente influenciada pelo pensamento de Schiller e pela estética de Hegel. No Brasil, este trabalho se consolidou principalmente a partir da contribuição de Koudela (1991) e Pupo (1999), autores que, tendo iniciado suas pesquisas na década de 1970, contribuíram para tornar a área de pesquisa acadêmica conhecida como Pedagogia do Teatro, um importante referencial na construção de uma política pública em Arte e Teatro.

O tema do jogo, através do qual os adolescentes 'brincam', mas ao mesmo tempo resolvem um problema de ordem estética, pode estar relacionado a aspectos da vida política do país, às diferenças raciais e culturais, a jogos e brincadeiras tradicionais ou a todo e qualquer tema proposto. Ao serem articulados no sistema de Jogos Teatrais, estes aspectos temáticos poderão conduzir a uma reflexão acerca dos valores éticos e das práticas sociais dos envolvidos. Busca-se assim devolver ao adolescente excluído o papel de um sujeito autônomo, que tem voz e direitos sociais e que interage com a vida da polis, estimulado pelo paedomo, o professor. Ao propor o resgate do sentido de ser cidadão

2 Para Castells (2000, p. 33), produção "é a ação da humanidade sobre a matéria (natureza) para apropriar-se dela e transformá-la em seu benefício, obtendo em produtos, consumindo (de forma irregular) parte dele e acumulando excedente para investimento conforme os vários objetivos socialmente determinados"; experiência "é a ação dos sujeitos sobre si mesmos determinada pela interação entre as identidades biológicas e culturais desses sujeitos em relação a seus ambientes sociais e culturais"; poder é aquela relação entre os sujeitos humanos que, com base na produção e na experiência impõem a vontade de alguns sobre os outros pelo emprego potencial ou real de violência física ou simbólica

3 IDH: Índice de Desenvolvimento Humano. O Brasil possuía a posição de número 59 no IDH do ano de 1996; estudos apontam que sua posição atual caiu para $79^{\circ}$. A Noruega é o primeiro da lista, sendo a Alemanha o $14^{\circ}$; países como Chile e Argentina estão entre a $30^{a}$ e a $35^{a}$ posição. O IDH é um estudo da ONU calculado a partir de três variáveis: longevidade, nível educacional e renda da população. 
para o jovem excluído, o Jogo Teatral busca articular nos indivíduos o que Sen (2001) chamou de "intitulamento" ou "capacidade". Isto significa provê-los de uma melhor capacitação para ler um mundo tão complexo, melhorando sua interação, poder de observação, espírito crítico e sensibilidade.

A prática teatral no processo de aprendizagem associa os campos da Educação (na forma de uma Pedagogia do Teatro), da Cultura e do Direito, diretamente relacionados não somente à produção simbólica de indivíduos e grupos em questão, mas também à necessidade destes atuarem num contexto de tamanha diversidade. Aí se instala a imagem, criada por Hegel, do homem cindido entre a carne e o espírito. Entre a necessidade da sobrevivência, marcada muitas vezes pela violência e pobreza na periferia planetária, e a liberdade construída precariamente no âmbito de suas práticas sociais, estes teens-periféricos vão encontrando seus canais, meios e estratégias de transformação e de apropriação do conhecimento.

Este sujeito, ao "negar as condições imediatas da sua existência e criar o novo como plenamente humano", é também potencial possuidor dos atributos da Sociedade em Rede, como a entende Manuel Castells (2000).

Nas periferias das megacidades, o conflito entre este homem da necessidade, às vezes esfacelado, usurpado na sua dignidade e no seu bem estar, e o homem da liberdade, nascido da utopia do Estado Moral de Schiller, dá-se de forma violenta, expressa uma nova complexidade do processo de aprendizagem. Nesses momentos, o educador tem que reconhecer que a idéia de uma política pública em cultura e educação só poderá sobreviver com o apoio e a concordância do público-alvo, os jovens, passando estes mesmos à condição de paedomos, co-educadores ou trabalhadores culturais.

Essa troca de papéis, na qual o educador passa à periferia do processo de aprendizagem e os jovens ao centro, sendo eles próprios os coproponentes das práticas pedagógicas, diz respeito a uma situação na qual a ruptura do contra- to social, contrato este tão aludido por Rousseau, obriga a pensar novas estratégias de ensinoaprendizagem. Essas novas estratégias precisam levar em conta vários aspectos, dentre os quais destacamos dois: o primeiro está relacionado à falência do Estado enquanto protetor do cidadão, principalmente no que diz respeito ao direito à educação e à cultura na periferia do sistema. Este primeiro aspecto força muitas vezes o educador a reconstruir o planejamento pedagógico a partir de zero, sempre levando em conta este progressivo desaparecimento, senão de direito, mas de fato, da figura jurídico-institucional do Estado.

O segundo aspecto está mais diretamente relacionado à atuação do educador e sua relação com o educando. Este, na medida em que foi expropriado pela ausência de um Estado regulador que lhe garanta os direitos, não verifica sentido em aprender a língua nacional, as fórmulas, datas e eventos históricos, nem toda a parafernália do currículo formal da escola. Ele rejeita o pacto com a comunidade escolar, e por extensão, com o Estado, o qual por sua vez almeja formá-lo. Este teen-periférico parte para o ataque, o que significa dizer que reconstrói destruindo a língua, os costumes e as tradições e termina por forçar a uma reformulação da estratégia pedagógica preparada pelo Estado, na figura da escola ou do educador. As atitudes de violência extrema e uso intenso de drogas, bem como a alta taxa de homicídios e crimes de toda ordem que partem da periferia, são somente a face mais visível desse ciclo perigoso e às vezes perverso. Isto demonstraria a absurda incapacidade do Estado em prover uma inserção mínima aos ditos excluídos sociais. Esta incapacidade torna-se manifesta através dos mecanismos de repressão adotados, compreendidos pela adoção de câmeras em salas de aula e de policiamento ostensivo dentro das unidades escolares.

A utopia de Schiller, expressa na construção do Homem Moral através da educação estética, é aqui transposta para o presente a um custo doloroso para todos os atores no processo, educadores e educandos, Estado e sociedade. 
As contradiçõos que surgem desta transposição, em tempo real, entre o homem da liberdade e o da necessidade, entre carne e espírito, entre Estética e Ética, terminam por clamar por uma nova ordem econômica, social e cultural num mundo globalizado, do qual contraditoriamente um dos principais fundamentos é o conceito de rupturas pós-coloniais.

A descolonização pedagógica e cultural desta outra América, situada ao sul do Equador, luso-afro-ameríndia, passa a contar então com um amplo espectro de estratégias, no campo da teoria e da prática, onde linguagens artísticas como o Teatro são deslocadas para o centro das políticas públicas em educação e cultura, e onde se dá o ritual ludofágico de desconstrução dos modelos eurocêntricos, que depois de digeridos são ressuscitados e ressignificados.

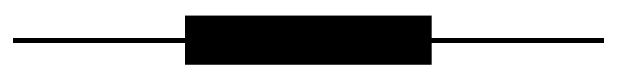

\section{Referências bibliográficas}

BRUNO, Lúcia Barreto Nuevo. Educação, qualificação e desenvolvimento econômico. In: Educação e trabalho no capitalismo contemporâneo. São Paulo: Atlas, 1996.

CASTELLS, Manuel. A sociedade em rede. São Paulo: Paz e Terra, 2000.

CHAUÍ, Marilena S. Política cultural, cultura política e patrimônio histórico. In: O Direito à memória: patrimônio histórico e cidadania. Prefeitura do Município de São Paulo / Departamento do Patrimônio Histórico, 1992.

GIROUX, Henry. Cruzando as fronteiras do discurso educacional. Porto Alegre: Artmed, 1999.

IPEA. Relatório do Programa das Nações Unidas para o Desenvolvimento - PNUD. Brasília: Instituto de Pesquisas Econômicas Aplicadas, 1996.

KOUDELA, Ingrid Dormien. Jogos teatrais. São Paulo: Perspectiva, 1984.

SEN, Amartya. Desenvolvimento como liberdade. São Paulo: Companhia das Letras, 2001. 